\title{
Developing a computer program for mathematical investigation of stepped planing hull characteristics
}

\author{
Afshin Loni, Parviz Ghadimi*, Hashem Nowruzi, Abbas Dashtimanesh \\ Department of Marine Technology, Amirkabir University of Technology \\ *Corresponding author E-mail:pghadimi@aut.ac.ir
}

\begin{abstract}
Few authors have investigated the behavior of stepped planing hulls, so far. However, effects of such hulls on planing craft performance indicate that it can be a great improvement and must be analyzed more precisely. For this purpose, a mathematical model which was previously developed based on Savitsky's formulation is implemented and the performance of a specific stepped planing hull is studied. Furthermore, a computer program is developed and effects of various parameters on stepped planing hull performance are investigated. Based on the obtained results, it is concluded that different heights of step leads to large variation of required power for the planing hull. Moreover, it can be mentioned that the parametric studies which are conducted in this article can be a good guide for engineering at initial design of a stepped planing hull.
\end{abstract}

Keywords: Stepped planing hulls; Mathematical Modeling;j Hydrodynamics; Savitsky’s method.

\section{Introduction}

Design of planing hulls is an important issue for naval architecture and marine engineers. Due to nonlinear nature of such hulls, it is very important to predict their performance at initial phase of the design. For this purpose, some authors have tried to study various aspect of planing hull design. One such design which was focused by researchers and engineers has been the stepped planing hull. This can be described by a hull which is divided along the transverse plane in to two hulls [1]. Steps have mainly been used to reduce the friction drag of the hull by diminishing the wetted surface area. Generally, a speed increase of 10 to 15 percent can be expected from a stepped hull compared to a non-stepped hull [2]. The proper choice of the shape of the stepped bottom may also offer some useful effects [3]. The design of a step that can perform effectively is very difficult and has to be done by complicated mathematical and experimental solutions. In continuation of the literature study, various related studies on stepped planing hull as well as mathematical modeling of such hulls are reviewed.

Stepped hulls have been used from very long time ago to improve performance. A very early famous design was Maple Leaf, built of wood in very early 1900s, and since then there have been many successful designs. However, first Scientific study on stepped planing hulls and their performance was considered by Baker in 1910 [4]. After that, the first comprehensive experiment which received wide attention was that of Sottorf in 1932 [5]. The studies of Sottorf later was followed by Shoemaker in 1934 [6] and Sedov in 1939 [7].

However, the most famous study which could predict the performance of a stepped hull was by Savitsky in 1964 [8]. Also, the paper by Savitsky and Morabito in 2010[1] provides a detailed and thorough review of the state-of-the-art developments in stepped hull hydrodynamics. Next, mathematical modeling of stepped hull has been presented. Results of an extensive series of model tests that define the longitudinal surface wake profiles aft of prismatic hulls having deadrise angles of $10^{\circ}, 20^{\circ}$ and $30^{\circ}$ are presented in their paper [1]. This problem followed up by savitsky and Brown in 1976 [9] Provide a set of semi-empirical equations for calculating floating status, power and stability in propoising. David Svahn in 2009 [10] developed a model for planing hull. Garland and Maki in 2012 [11] presented a paper titled "A Numerical Study of a Two-Dimensional Stepped Planing Surface" and investigated the performance of a stepped planing hull through numerical simulation of the fully nonlinear flow under a two-dimensional body.

As mentioned before, one important issue about the stepped hulls is that there are so many factors that can affect their performance and usually there exists only one configuration that can lead to the best result in terms of performance. Main aim of the current study is to developing a computer program for simulation of the stepped planing hulls characteristics. Moreover, study of various parameters affecting the stepped planing hull performance is investigated, 
thoroughly. For this purpose, four different factors that can affect the performance of a stepped planing hull have been studied, systematically. The considered factors are the height of step, the distance of the step from transom, the beam of planing hull and the angle at which thrust affects the transom from keel line. Overall, 38 different cases are investigated and the results for the best performance of the stepped hull have been presented.

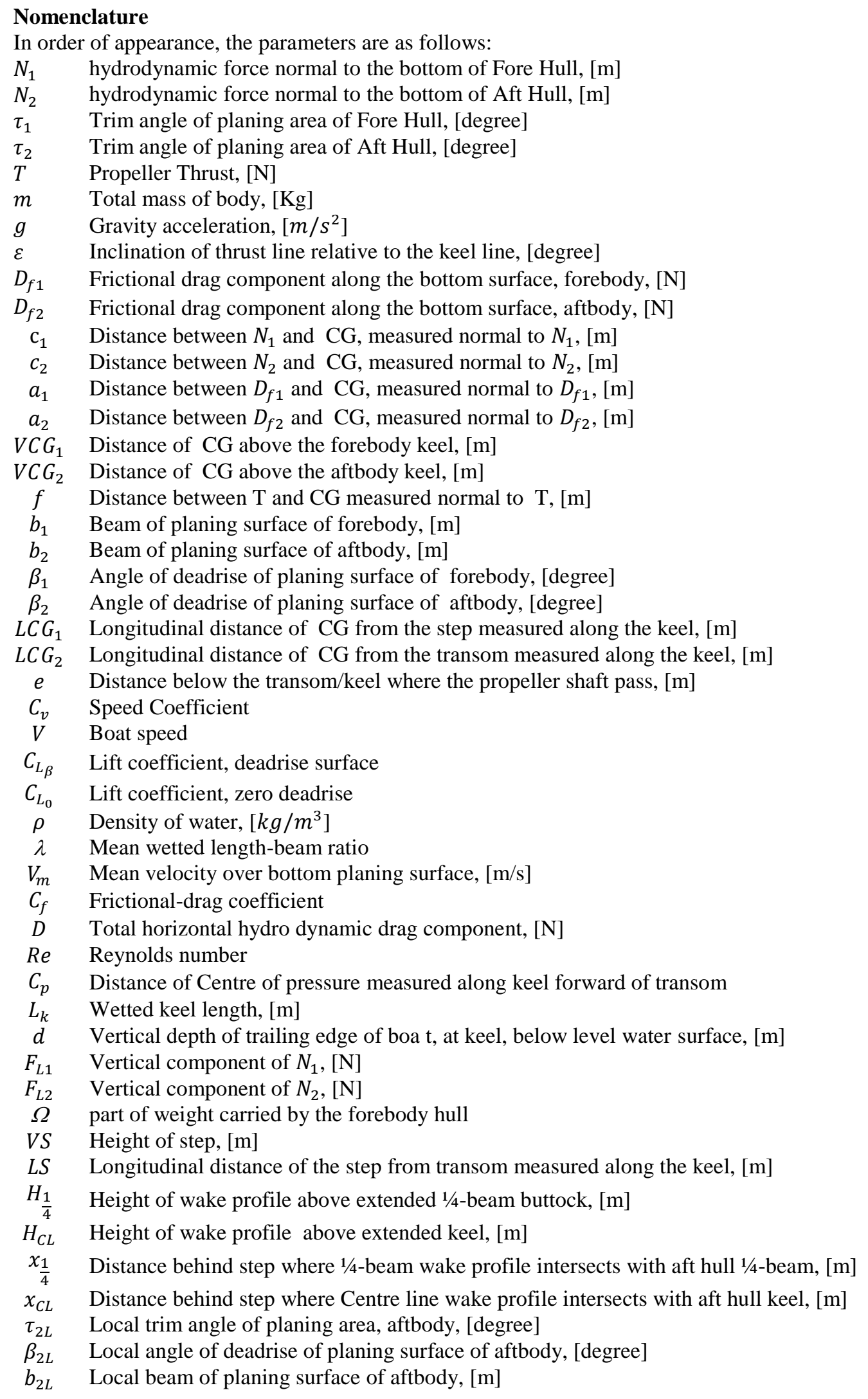


$\varphi \quad$ Angle between the keel in front, and keel behind the step, [deg]

$L_{12} \quad$ Difference between wetted keel and wetted chine lengths on the aftbody, [m]

$L_{2_{2}} \quad$ Difference between keel and chine lengths wetted by level water surface on the aftbody, [m]

$\lambda_{2 \mathrm{~L}} \quad$ Local mean wetted length-beam ratio on the aftbody

\section{Mathematical modeling}

As stated before, the implemented method for calculation of performance had generally been developed by Savitsky[8] which was subsequently extended for stepped planing hulls by Svahn [10].

It is assumed that the craft is in steady state which basically means that the speed is constant and acceleration in all directions is zero. The equilibrium in vertical and horizontal directions, as shown in Fig.1, can be calculated from the equations.

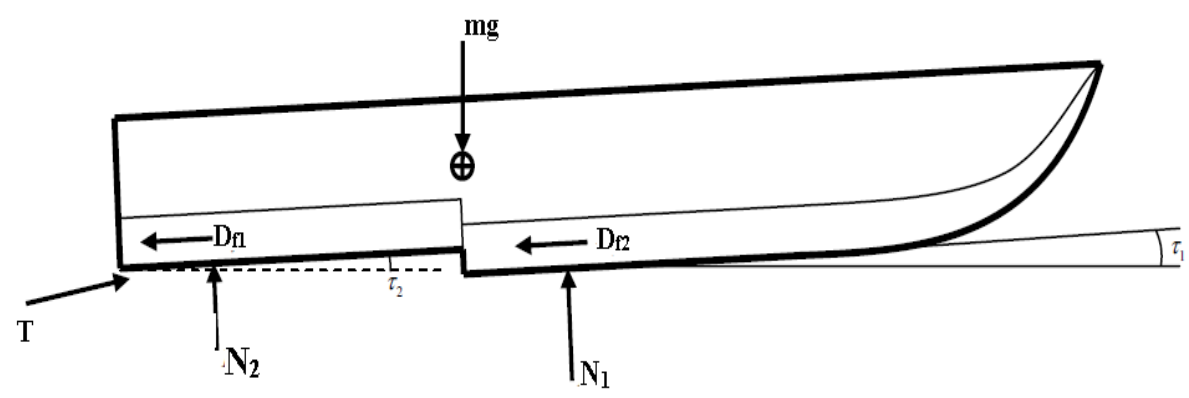

Figure 1: Equilibrium of stepped planing hull.

$\uparrow: N_{1} \cos \tau_{1}+N_{2} \cos \tau_{2}+T \sin \left(\tau_{2}+\varepsilon\right)-m g-D_{f 1} \sin \tau_{1}-D_{f 2} \sin \tau_{2}=0$

$\rightarrow: \operatorname{Tcos}\left(\tau_{2}+\varepsilon\right)-N_{1} \sin \tau_{1}-N_{2} \sin \tau_{2}-D_{f 1} \cos \tau_{1}-D_{f 2} \cos \tau_{2}=0$

For calculation of the moment equilibrium there are so many factors that should be put into account. Figure 2 shows the forces and their arm.

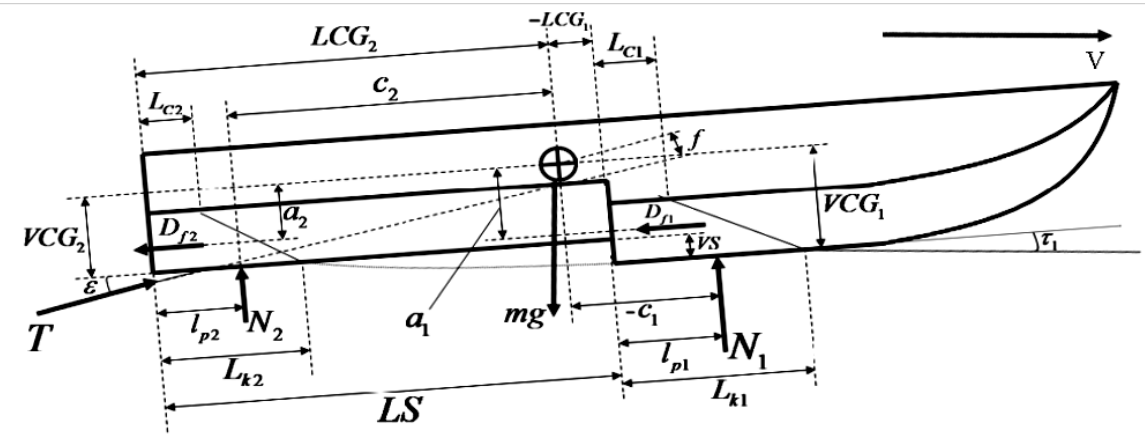

Figure 2: Complete Geometry of stepped planing hull.

$C G=N_{1} c_{1}+N_{2} c_{2}+D_{f 1} a_{1}+D_{f 2} a_{2}-T . f$

Where,

$a_{1}=V C G_{1}-\frac{b_{1}}{4} \tan \beta_{1}$

$a_{2}=V C G_{2}-\frac{b_{2}}{4} \tan \beta_{2}$

$f=\left(V C G_{2}+e\right) \cos \varepsilon-L C G_{2} \sin \varepsilon$

The calculations related to the first hull are exactly like Savitsky's original method. In this method, the equilibrium of pitching moment is being investigated for a given trim. If the equilibrium is satisfactory, then the trim is right, otherwise; another trim should be given and all calculations should be performed over again. The required inputs for starting the calculation are:

- Mass[kg], 


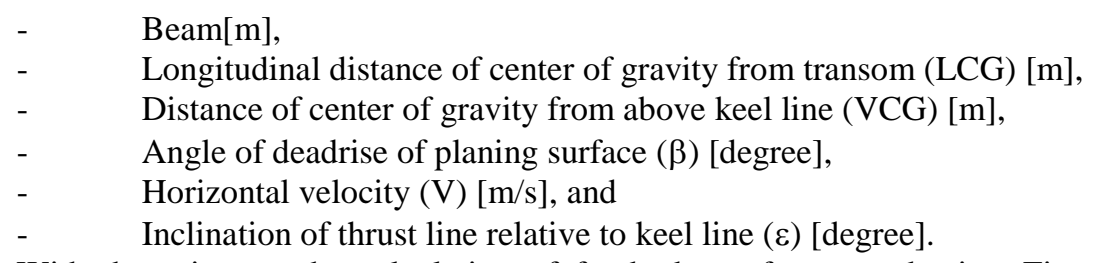

With these inputs, the calculation of forebody performance begins. First, two coefficients that don't change with different trims are calculated; Froude numbers with respect to the beam $\left(C_{v}\right)$ and Lift coefficient $\left(C_{L_{\beta}}\right)$ as in

$C_{v}=\frac{V}{\sqrt{g b}}$

$C_{L_{\beta}}=\frac{m g}{\frac{1}{2} V^{2} b^{2} \rho}$

After calculating these two coefficients with the mentioned equations, the frictional drag can be calculated. Firstly, the aspect ratio can be calculated by equations 9 and 10 , which are semi empirical.

$C_{L_{\beta}}=C_{L_{0}}-0.0065 \beta C_{L_{0}}^{0.60}$

$C_{L_{0}}=\tau^{1.1}\left(0.0120 \lambda^{1 / 2}+\frac{0.0055 \lambda^{5 / 2}}{C_{v}^{2}}\right)$

Subsequently, a mean velocity is calculated given from Bernoulli's equation.

$V_{m}=V\left[1-\frac{0.0120 \lambda^{1 / 2} \tau^{1.1}-0.0065 \beta\left(0.0120 \lambda^{1 / 2} \tau^{1.1}\right)^{0.60}}{\lambda \cos \tau}\right]^{1 / 2}$

Then, by calculating the friction coefficient the frictional drag can be found as follows:

$C_{f}=\frac{0.075}{\left(\log _{10}(R e)-2\right)^{2}}$

$R e=V_{m} \lambda \frac{b}{v}$

$D_{f}=\frac{1}{2} \frac{\rho V_{m}^{2} \lambda b^{2}}{\cos \beta}\left(C_{f}+\Delta C_{f}\right)$

The factor $\Delta C_{f}$ is 0.0004 due based on ATTC standard roughness. Using equations (15) through (20), Drag and vertical force $(\mathrm{N})$ and their distance from center of gravity are calculated. Finally, the pitching moment can be calculated by equation 20.

$m g=N \cos \tau \Rightarrow N=\frac{m g}{\cos \tau}$

$D=m g \tan \tau+\frac{D_{f}}{\cos \tau}$

$C_{p}=0.75-\frac{1}{\frac{5.21 C_{v}^{2}}{\lambda^{2}}+2.39}$

$c=L C G-l_{p}=L C G-C_{p} \lambda b$

$a=V C G-\frac{b}{4} \tan \beta$

$M_{t o t}=m g\left[\frac{c}{\cos \tau}(1-\sin \tau \sin (\tau+\varepsilon))-f \cdot \sin \tau\right]+D_{f}(a-f)$

As stated before, the total pitching moment from eq.20 (with the right trim ) should be set equal to zero. If this moment was negative then the trim is increased by 1 , and all the above stages will repeat. This iteration will continue until a 
positive moment reached with a given trim. At this point, the exact trim is a number between the last two given trims and can be calculated by interpolation.

The length of wetted keel for the forebody $\left(\mathrm{L}_{\mathrm{k}}\right)$ and draft $(\mathrm{d})$ is required for performing the calculations of aftbody.

$L_{k}=\lambda_{e} b+\frac{b \tan \beta}{2 \pi \tan \tau_{e}}$

$d=L_{k} \sin \tau_{e}$

The problem with calculating the performance of forebody in a stepped planing hull is that the weight distribution between fore and aftbody is unknown. Therefore, without exact value of mass of forebody, the calculations cannot be performed. This problem has to be remedied by using another initial guess, exactly like the one performed with trim. Usually, the weight of forebody is more than $60 \%$ of the whole body.

$F_{L 1}=\Omega . m g$

where $\Omega$ is assumed to be 0.6 , at first. With this assumption, the wetted length can be found through equations (7) to (10) and (22). It is obvious that $\Omega . m g$ shall be used instead of $m g$ in these equations. When this is done, the calculations of forebody begin.

In this stage, using given wetted length and implementing the wake theory [1], some empirical equations can be extracted which lead to finding the local conditions. Local conditions like local trim and local deadrise, among others are used to calculate the performance of aftbody.

$V S+x_{C L} \tan \varphi=H_{C L}\left(x_{C L}\right)$

$=b_{1} .0 .17\left(1.5+0.03 \frac{L_{k_{1}}}{b_{1}} \tau_{1}^{1.5}\right) \sin \left(\frac{\pi}{C_{V 1}}\left(\frac{x_{C L}}{3 b_{1}}\right)^{1.5}\right)$

$V S+$ 0.25. $b_{1}\left(\tan \beta_{1}+\tan \beta_{2}\right)+x_{\frac{1}{4}} \tan \varphi=H_{\frac{1}{4}}\left(x_{\frac{1}{4}}\right) \quad 10^{\circ} \leq \beta_{1} \leq 30^{\circ}$

$=b_{1} \cdot 0.17\left(0.75+0.03 \frac{L_{k_{1}}}{b_{1}} \tau_{1}^{1.5}\right) \sin \left(\frac{\pi}{C_{V 1}}\left(\frac{x_{1 / 4}}{3 b_{1}}\right)^{1.5}\right)$

These two equations are experimentally extracted from wake theory which represents the height and distance of center line (CL) and 1/4 of buttock line from where water intersects the keel.

By having $x_{1 / 4}$ and $x_{C L}$, the local deadrise and local trim can be calculated from following equations:

$\tau_{2 L}=0.17\left[0.75+0.03 \frac{L_{k_{1}}}{b_{1}} \tau_{1}^{1.5}\right] \frac{1}{2} \frac{\pi}{C_{V 1}}\left(\frac{x_{1 / 4}}{3 b_{1}}\right)^{0.5} \cos \left(\frac{\pi}{C_{V 1}}\left(\frac{x_{1 / 4}}{3 b_{1}}\right)^{1.5}\right)-\varphi$

$\beta_{2 L}=\beta_{2}-\arctan \frac{H_{1 / 4}\left(x_{1 / 4}\right)+0.25+b_{2} \tan \beta_{1}-H_{C L}\left(x_{1 / 4}\right)}{0.25 b_{2}}$

Another local condition that should be calculated by wake theory is local beam of aft hull $\left(b_{2 L}\right)$, and local aspect ratio of aft hull $\left(\lambda_{2 \mathrm{~L}}\right)$ which can be extracted from following equations.

$L_{2_{2}}=2 \frac{x_{1 / 4}-x_{C L}}{\cos \varphi}$

$b_{2 L}=\frac{2 L_{22} \tan \tau_{2 L}}{\tan \beta_{2 L}}$

$L_{12}=\frac{b_{2 L} \tan \beta_{2 L}}{\pi \tan \tau_{2 L}}$

$\lambda_{2 \mathrm{~L}}=\frac{L_{k 2}}{b_{2 L}}-\frac{L_{1_{2}}}{2 b_{2 L}}$

Now, using these local conditions, the total lift of aft hull $\left(\mathrm{F}_{\mathrm{L} 2}\right)$ can be calculated as follows:

$C_{V 2}=\frac{V}{\sqrt{g \cdot b_{2 L}}}$

$C_{L 0_{2}}=\tau_{2 L}{ }^{1.1}\left(0.0120 \lambda_{2 L}{ }^{0.5}+\frac{0.0055 \lambda_{2 L}{ }^{2.5}}{C_{V 2}^{2}}\right)$

$C_{L \beta_{2}}=C_{L 0_{2}}-0.0065 \beta_{2 L} C_{L 0_{2}}^{0.60}$

$F_{L 2_{L}}=\frac{1}{2} C_{L \beta_{2}} \rho V^{2} b_{2 L}^{2} \cdot \cos \left(\beta_{2}-\beta_{2 L}\right)$

$F_{L 2}=F_{L 2_{L}} \cos \left(\tau_{2}-\tau_{2 L}\right)$ 
When $F_{L 2}$ is found, the accuracy of assumed $\Omega$ can be tested:

$F_{L 1}+F_{L 2}-m g=\gamma$

$\gamma$ Is a tolerance which shows the error of a given $\Omega$. The acceptable absolute value of tolerance should not be less than 200. If the condition $|\gamma|<200$ in eq.(37) is satisfied, the given $\Omega$ is satisfactory. If not, another value $\Omega$ has to be guessed. From the following equation, a better $\Omega$ can be guessed which leads to a more accurate assumption:

$\Omega_{n+1}=\frac{\frac{m g-F_{L 2}}{m g}+\Omega_{n}}{2}=\frac{1}{2}+\frac{F_{L 1}-F_{L 2}}{2 m g}$

When the vertical equilibrium for one given trim is achieved, it is time to check the total pitching moment for that trim. First, the total drag force of forebody can be found from equation (14) which can then be used to calculate the total drag and vertical force, $(\mathrm{N})$ of forebody. The formulas for finding the drag force of aftbody are exactly the same as forebody given in eqs. 9 to 16 , although it is obvious that all local conditions should be used instead.

$D_{1}=\Omega \cdot m g \tan \tau_{1}+\frac{D_{f 1}}{\cos \tau_{1}}$

The distances $\mathrm{D}_{\mathrm{f} 1}$ and $\mathrm{D}_{\mathrm{f} 2}$ shown in figure can be calculated by the following equations.

$a_{1}=V C G_{1}-\frac{b_{1}}{4} \tan \beta_{1}$

$a_{2}=V C G_{2}-\frac{b_{2}}{4} \tan \beta_{2}$

Vertical force can be calculated from following equations and their distance (c) is extracted from equations (17) and (18).

$N_{1}=\Omega \frac{m g}{\cos \tau_{1}}=\frac{F_{L 1}}{\cos \tau_{1}}$

$N_{2}=\frac{(1-\Omega) m g}{\cos \tau_{2}}=\frac{F_{L 2}}{\cos \tau_{2}}$

Finally, using the computed forces, the pitching equilibrium can be checked:

$N_{1} c_{1}+N_{2} c_{2}+D_{f 1} a_{1}+D_{f 2} a_{2}-T . f=0$

It is important to know that the thrust force can be calculated by the horizontal equilibrium of hull which is written in eq.(2). When all these calculations are done, the exact trim and all other necessary factors can be found within interpolation, as mentioned before.

\section{Computational procedure}

This numerical study has been accomplished by a MATLAB program based on the extracted mathematical equations. The process of inserting the equations in the code is exactly similar to the process explained in the previous section. However, a flowchart is presented for better understanding of how the program works. By using thirteen primary parameters as input, the calculation begins. Computational Algorithm can be seen in Fig.3.

\section{Validation case}

An example of Svan's paper has been used as a validation case. In this example, a planing body with the following characteristics is studied:

$\begin{array}{llcl}m & 4000 \mathrm{~kg} & L S & 2.5 \mathrm{~m} \\ V S & 0.5 \mathrm{~m} & L C G_{2} & 2.6 \mathrm{~m} \\ \beta_{1} & 11^{\circ} & V C G_{1} & 0.5 \mathrm{~m} \\ \beta_{2} & 10^{\circ} & b_{1} & 2 \mathrm{~m} \\ \varphi & 0^{\circ} & b_{2} & 2 \mathrm{~m} \\ \varepsilon & 0^{\circ} & V & 35 \text { knots } \\ e & 0.15 \mathrm{~m} & & \end{array}$

Outputs in the form of total Drag, EHP and trim are compared with the results of Svan's as shown below: 


\begin{tabular}{|l|l|l|}
\cline { 2 - 3 } \multicolumn{1}{c|}{} & Svan's (our) Results & Calculated Results \\
\hline Trim & $4.4^{\circ}$ & $4.64^{\circ}$ \\
\hline Total Drag & $5229 \mathrm{~N}$ & $5186 \mathrm{~N}$ \\
\hline Total EHP & $128 \mathrm{hp}$ & $125 \mathrm{hp}$ \\
\hline
\end{tabular}

Error percentages for EHP, drag, and trim are about 2\%, 0.8\%, and 5\%, respectively. This range of error may seem quite natural due to the number of used decimals.

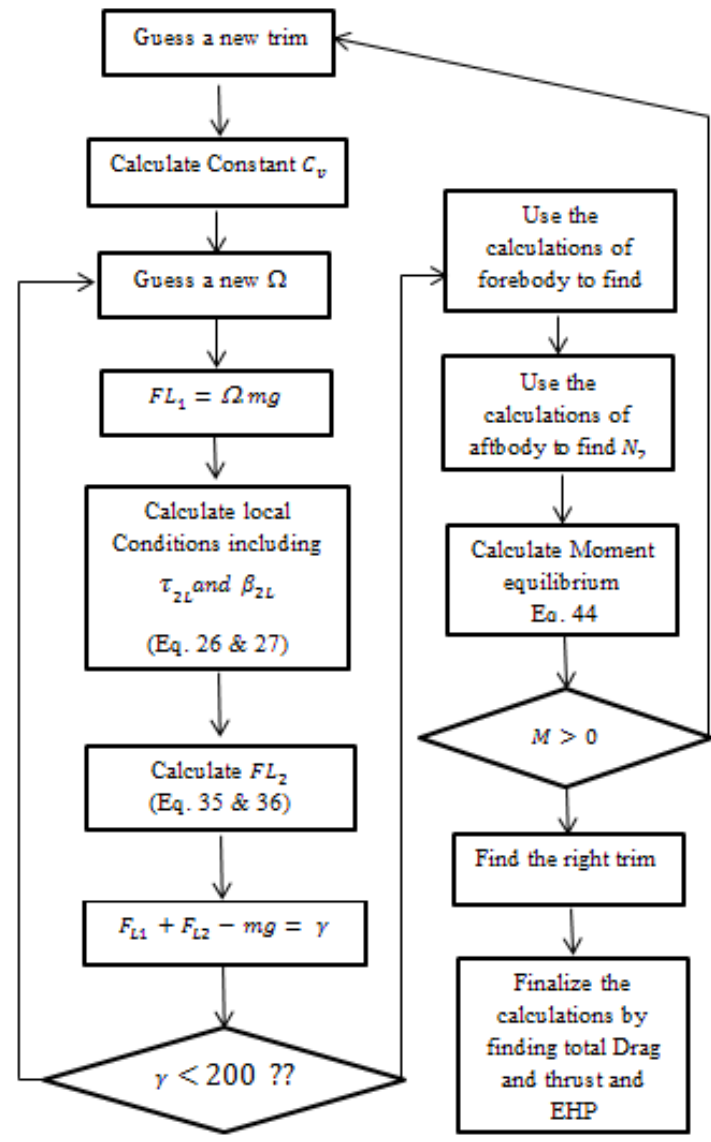

Figure 3: Computational Algorithm.

\section{Case study, results and discussions}

The studied case in this article is a planing hull with listed characteristics in Table 1.

Table 1: Constant Variables of the Studied Stepped Hull.

\begin{tabular}{|l|l|}
\hline Mass $(\mathrm{Kg})$ & 4000 \\
\hline $\mathrm{VS}(\mathrm{m})$ & 0.05 \\
\hline $\mathrm{LS}(\mathrm{m})$ & 2.5 \\
\hline $\mathrm{LCG}_{2}(\mathrm{~m})$ & 2.6 \\
\hline $\mathrm{VCG}_{1}(\mathrm{~m})$ & 0.5 \\
\hline $\mathrm{B}_{1}(\mathrm{~m})$ & 2 \\
\hline $\mathrm{B}_{2}(\mathrm{~m})$ & 2 \\
\hline $\mathrm{e}(\mathrm{m})$ & 0.15 \\
\hline$\beta_{1}($ degree $)$ & 11 \\
\hline$\beta_{2}$ (degree) & 10 \\
\hline$\varepsilon($ degree $)$ & 0 \\
\hline$\varphi($ degree $)$ & 0 \\
\hline $\mathrm{V}($ knots $)$ & 35 \\
\hline
\end{tabular}


In this study, effects of four different parameters are investigated which are as follows:

1. The height of step (VS)

2. The distance of step from transom (LS)

3. Beam (b1 and b2)

4. The angle at which thrust affects the transom $(\varepsilon)$.

For each case, ten different values are given as input and other values are constant, as shown in the table 2.

\begin{tabular}{|l|l|l|l|}
\multicolumn{2}{|c|}{ Table 2: Case Studies. } & Case 4 \\
\hline Case 1 & Case 2 & Case 3 & $\varepsilon$ \\
\hline VS & LS & b1 \& b2 & 0 \\
\hline 0.045 & 2.2 & 1.00 & 10 \\
\hline 0.047 & 2.3 & 1.25 & 20 \\
\hline 0.050 & 2.4 & 1.50 & 30 \\
\hline 0.052 & 2.5 & 1.75 & 40 \\
\hline 0.055 & 2.6 & 2.00 & 50 \\
\hline 0.056 & 2.7 & 2.25 & 60 \\
\hline 0.057 & 2.8 & 2.50 & 70 \\
\hline 0.060 & 2.9 & 2.75 & - \\
\hline 0.065 & 3.0 & 3.00 & - \\
\hline 0.070 & 3.1 & 3.25 & \\
\hline
\end{tabular}

When these values are chosen as input parametric studies, different outputs would be obtained. The most important factors that are affected by these values and have been studied are:

1) $\frac{\text { AftLift }}{\text { TotalLift }}$ Ratio: This represents the ratio of the lift distribution in the whole body. Whenever this ratio increase, the performance gets better.

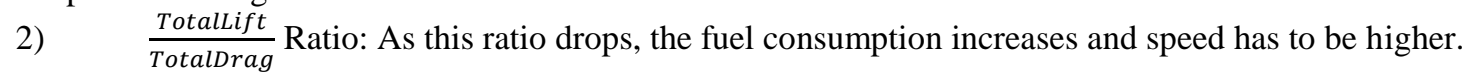

3) Trim angle: As this angle decreases, the equilibrium of the whole body is better.

4) EHP (effective Horse Power): This is the required power to put the body in the desired speed, as long as speed is constant. The less this factor, the more economical the planing body would be.

5) Reattachment Length.

These factors are studied in this paper and the charts of results are shown illustrated.

\subsection{CASE 1: VS as a variable}

The results of $\frac{\text { AftLift }}{\text { TotalLift }}$ and $\frac{\text { TotalLift }}{\text { TotalDrag }}$ ratios at the different heights of step (VS) can be seen in Fig.4. In addition, the results of Trim and EHP at different VS can be seen respectively in Figs.5 and 6.

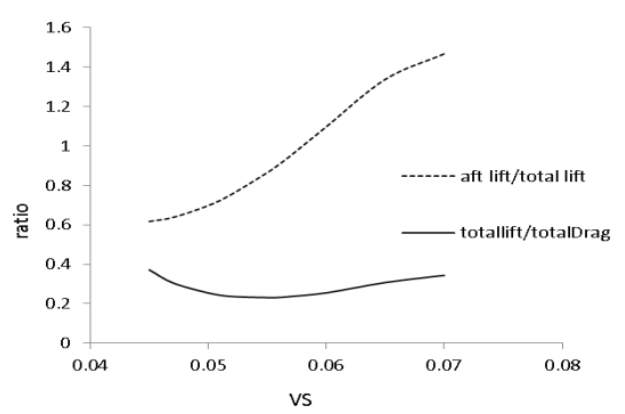

Figure 4: $-\frac{\text { AftLift }}{\text { TotalLift }}$ and $\frac{\text { TotalLift }}{\text { TotalDrag }}$ ratio at different VS. 


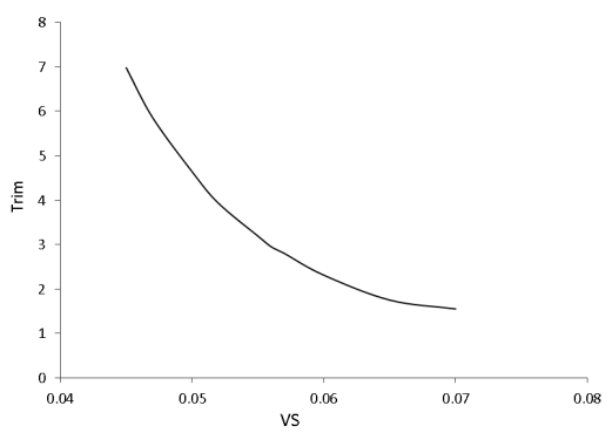

Figure 5: Trim at different VS.

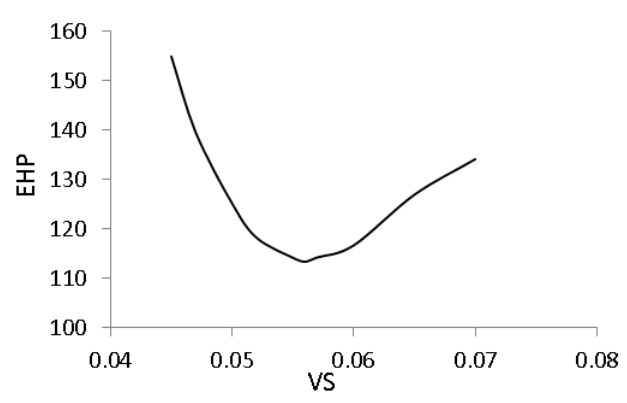

Figure 6: Effective Horse Power at Different VS.

As seen in the above figures, trim and EHP can be different, noticeably. It is obvious that in this case, the best range of VS is between "0.05" to "0.06" meters. In this range, the required power (EHP) is minimum, while the Trim decreases and the $\frac{\text { AftLift }}{\text { TotalLift }}$ ratio increases. So, three factors are in good condition. Also, the $\frac{\text { TotalLift }}{\text { TotalDrag }}$ ratio is approximately constant and doesn't make a lot difference.

Figure 7 illustrates the results of reattachment length in different cases of VS.

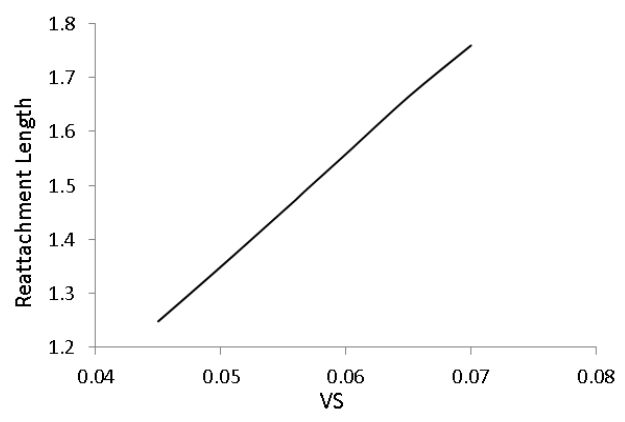

Figure 7: Reattachment Length at Different VS.

As seen in the above Fig.7, the reattachment length increasing approximately linearity with increasing of Vs.

\subsection{CASE 2 (LS as variable)}

The results of $\frac{\text { AftLift }}{\text { TotalLift }}$ and $\frac{\text { TotalLift }}{\text { TotalDrag }}$ ratios at different distances of step from the transom (LS) can be seen in Fig.8. In addition, the results of Trim and EHP at different cases of LS can be seen respectively in Figs.9 and 10. 


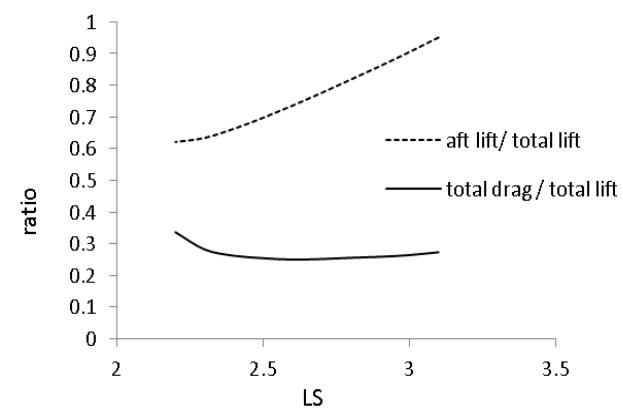

Figure 8: $\frac{\text { AftLift }}{\text { TotalLift }}$ and $\frac{\text { TotalLift }}{\text { TotalDrag }}$ ratio at Different LS.

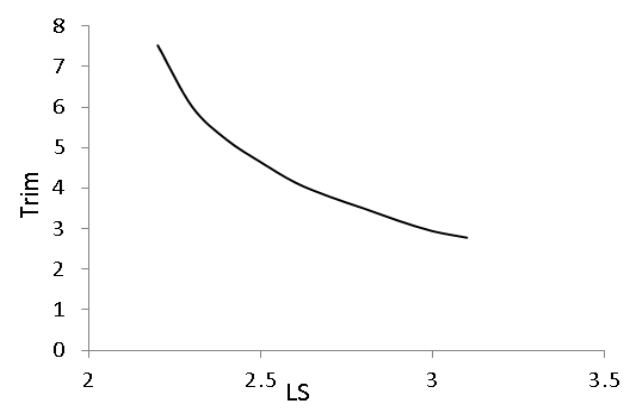

Figure 9: Trim at Different LS.

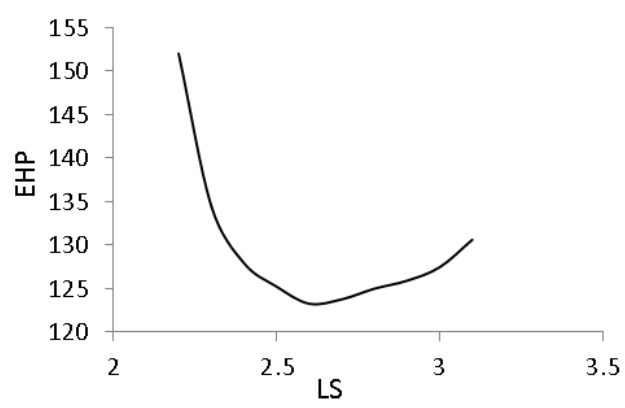

Figure 10: Effective Horse Power at Different LS.

In this particular case, the best range of LS is between "2.5" to "3.0" meters and EHP is minimum, while trim decreases and $\frac{\text { AftLift }}{\text { TotalLift }}$ increases. The $\frac{\text { TotalLift }}{\text { TotalDrag }}$ ratio is still constant approximately and cannot make so much difference. It is also better that to put the LS nearer to 3 meters, because when approaching the length of 3 meters, although the EHP increases, but there is not very noticeable difference, while the decrease in trim is more acceptable.

Fig. 11 illustrates the results of reattachment length at different cases of LS.

As seen in Fig.11, the reattachment length increases approximately exponentially concave upward with an increase in LS.

\subsection{CASE $3\left(b_{1} \& b_{2}\right.$ as variables)}

The results of $\frac{\text { AftLift }}{\text { TotalLift }}$ and $\frac{\text { TotalLift }}{\text { TotalDrag }}$ ratios at different cases of Beams $\left({ }_{1} \& b_{2}\right)$ can be seen in Fig.12. Furthermore, the results of Trim and EHP at different cases $b_{1} \& b_{2}$ are represented respectively in Figs.13 and 14. 


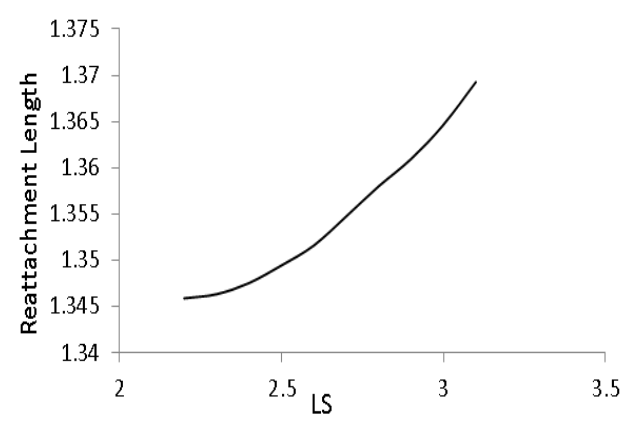

Figure 11: Reattachment Length at differnet LS.

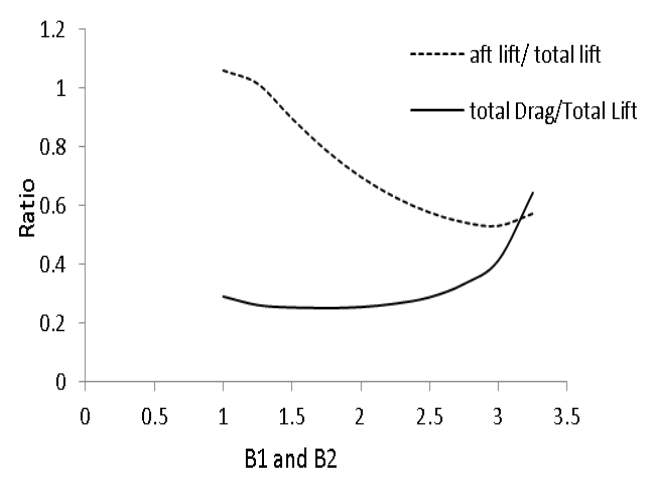

Figure 12: $\frac{\text { AftLift }}{\text { TotalLift }}$ and $\frac{\text { TotalLift }}{\text { TotalDrag }}$ ratio at Different Beams.

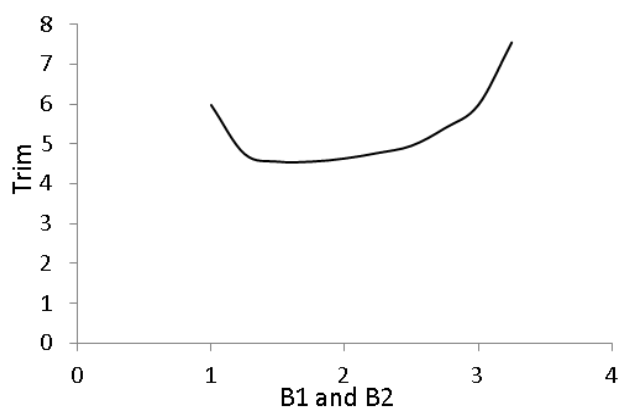

Figure 13: Trim at different Beams.

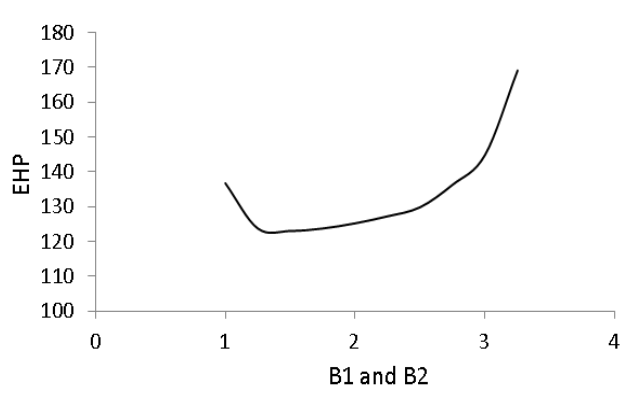

Figure 14: Effective Horse Power at different Beams.

In this case of study as shown in the charts, the $\frac{\text { TotalLift }}{\text { TotalDrag }}$ ratio increases rapidly after the beam of 2.5. Therefore, it is not optimal after this quantity. Also, by decreasing the beam, the $\frac{\text { AftLift }}{\text { TotalLift }}$ ratio increases which is acceptable. Thus, the best range for beam is form " 1.5 " to " 2.5 " meters. However, in this particular case, there is one more thing that must be 
considered, and that is the aspect ratio " $\lambda$ ". When the beam decreases, as a result the aspect ratio decreases and this may lead to a heaving problem.

Figure 15 illustrates the results of reattachment length at different cases of $b_{1} \& b_{2}$.

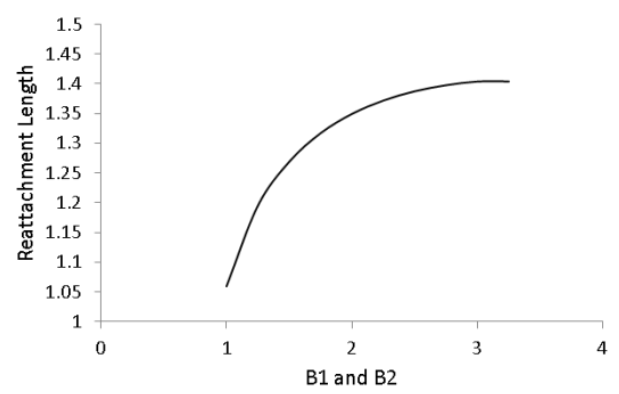

Figure 15: Reattachment length at different Beams.

As seen in Fig.15, the reattachment length increases approximately exponentially concave downward with an increase in $b_{1} \& b_{2}$.

\section{4: CASE 4 ( $\varepsilon$ as variable)}

The results of $\frac{\text { AftLift }}{\text { TotalLift }}$ and $\frac{\text { TotalLift }}{\text { TotalDrag }}$ ratios at different cases of the angle at which thrust affects the transom $(\varepsilon)$ can be seen in Fig.16. In addition, the results of Trim and EHP at different cases of $\varepsilon$, represented respectively in Figs.17 and 18.

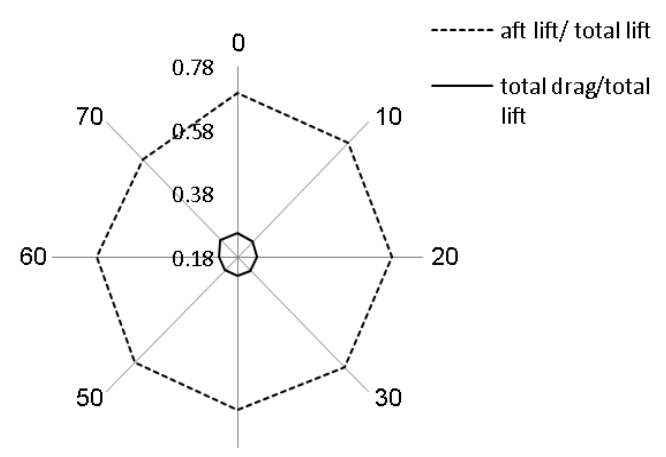

Figure 1: $\frac{\text { AftLift }}{\text { TotalLift }}$ and $\frac{40}{\text { TotalLift }}$ raldios at different $\varepsilon$.

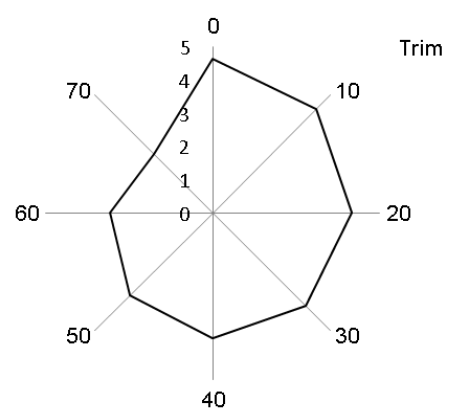

Figure 2: Trim at different $\varepsilon$ 


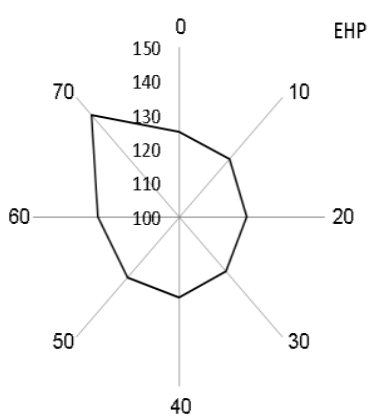

Figure 3: Effective Horse Power at different $\varepsilon$.

In this final case, it is obvious from the charts that by increasing " $\varepsilon$ " to 60 degrees, there would be a noticeable decrease in trim and $\frac{\text { TotalLift }}{\text { TotalDrag }}$ ratio, while the increase in EHP is low and can be neglected. Also, there is a small decrease in $\frac{\text { AftLift }}{\text { TotalLift }}$ ratio that can be abandoned in comparison with a decrease in trim.

Figure 19 illustrates the results of reattachment length at different cases of $\varepsilon$.

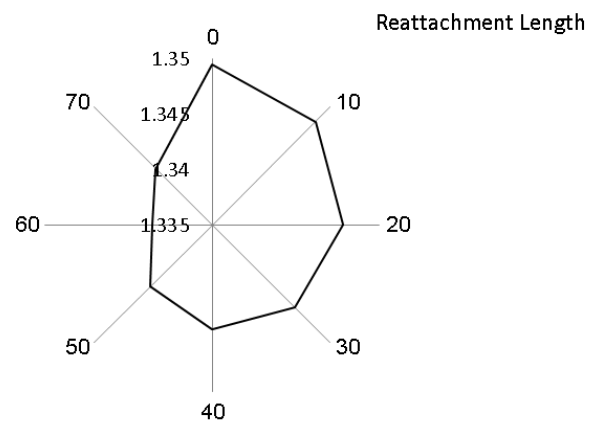

Figure 4: Reattachment Length at Different $\varepsilon$.

As seen in the above figure, the reattachment length decreases with an increase in $\varepsilon$.

1. The height of step (VS)

2. The distance of step from transom (LS)

3. Beam (b1 and b2)

4. The angle at which thrust affects the transom $(\varepsilon)$.

\section{Conclusion}

This study which was basically performed using Savitsky's method was indicative of the importance of step in a planing hull. It certainly illustrates that how accurate and punctilious a design of stepped planing hull should be.

What can be inferred from this investigation is that some factors in a stepped planing hull are extremely important and can change the whole performance of the planing hull by a very small change. Needless to say that the most important factor here is the height of step (VS) which can make great difference if decreased or increased by only one centimeter. The distance of step from transom (LS) is also important and can help decrease the trim angle and EHP. Two other factors of beam and $\varepsilon$ are also important for making a planing hull more economical and more stable. These two factors can also be considered in a non-stepped planing hull and are so important to be studied.

This study also shows that for each case considered, the result may lead to a different conclusion, while there can be a few optimal result for each case.

As mentioned before, there are so many other factors that can affect the performance of a stepped planing hull. One factor that has not been studied in this paper and can be experimented in future work is deadrise angle. As long as it is known, the difference in deadrise angle can lead to different trim angles and different values of EHP. 


\section{References}

[1] Daniel Savitsky, Michael Morabito, "Surface Wave Contours Associated With The Forebody Wake of Stepped Planing Hulls",Marine Technology, Volume 47, January 2010.

[2] "Stepped Hull", www.navaldesign.co.za.

[3] Michael V. Makasyeyev, "Numerical Modeling of Cavity Flow on Bottom of A Stepped Planing Hull", Proceedings of the 7th International Symposium Cavitation, Paper no. 116, August 2009.

[4] Korvin-Kroukovsky B.V., Savitsky D., Lehman W.F., "Wetted Area and Center of Pressure of Planing Surfaces", Report SIT-DL-49-9-360 Davidson Laboratory Stevens Institute of Technology. Hoboken, New Jersey (USA), 1949.

[5] Sottorf, W. "Versuche mit Gleitflächen. Werft-Reederei-Hafen", [English version: "Experiments with Planing Surfaces", Report NACA TM 739, Washington, D.C. (USA), 1934.

[6] Shoemaker, J. M. "Tank Tests Of Flat and V-Bottom Planing Surfaces", Report NACA TN 509, Washington, D.C. (USA), 1934.

[7] Sedov, L.I. "Scale Effect and Optimum Relations for Sea Surface Planing", Report n.409 Central Aero-Hydrodynamical Institute, Moskva. [English version: "Scale Effect and Optimum Relations for Sea Surface Planing", Report NACA TM 1097, 1947. Washington, D.C. (USA), 1939.

[8] Savitsky, D., "Hydrodynamic Design of Planning Hulls", Marine Technology, Vol. 1, No. 1, pp. $71-95.1964$.

[9] Savitsky, D., Brown, P.W., "Procedures for Hydrodynamic Evaluation of Planning Hulls in Smooth and Rough Water", Marine Technology, Vol. 13, No. 4, pp. 381-400. 1976.

[10] David Svahn, "Performance Prediction Of Hulls With Transverse Steps", Master Thesis, Marina System Centre for Naval Architecture, KTH University, June 2009.

[11] William R. Garland, Kevin J. Maki, "A Numerical Study of a Two-Dimensional Stepped Planing Surface", Journal of Ship Production and Design, Vol. 28, No. 2, pp. 60-72, May 2012. 